
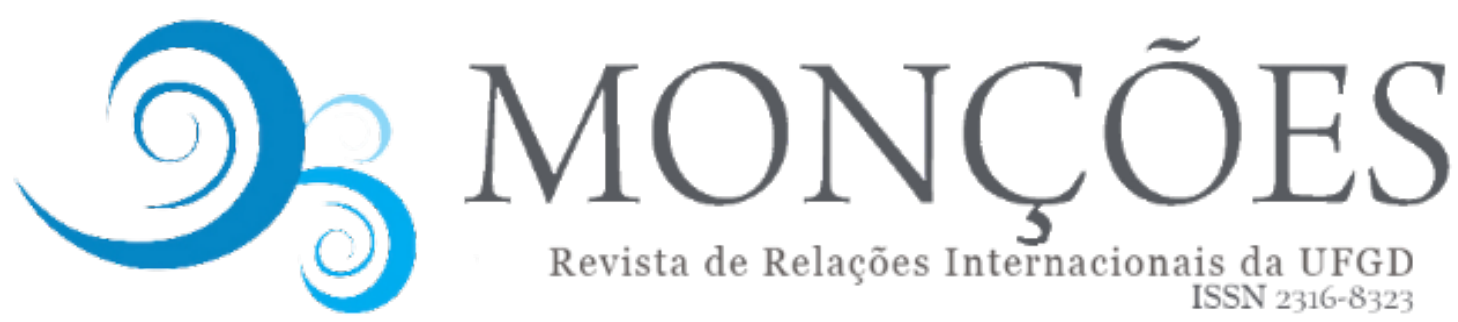

ISSN 2316-8323

\title{
O PROCESSO DE TEORIZAÇÃO EM RELAÇÕES INTERNACIONAIS NO BRASIL: UMA ANÁLISE A PARTIR DAS PRODUÇÕES EM PUC-RJ E UFRGS
}

\author{
JOCIELI DECOL \\ Mestranda em Sociologia e Ciência Política (UFSC)
}

IGOR CASTELLANO DA SILVA (UFSM)

Professor Adjunto do Departamento de Economia e Relações Internacionais (UFSM)

\begin{abstract}
RESUMO: Esta pesquisa trata do processo de construção do conhecimento em Relações Internacionais (RI). Direciona-se à análise da construção de Teorias de Relações Internacionais (TRI) do Sul Global, e mais especificamente, do Brasil no século XXI. O objetivo principal é compreender o processo de teorização em Relações Internacionais no país a partir da análise das teses de doutorado elaboradas na área, da Pontifícia Universidade Católica do Rio de Janeiro (PUC-RJ) e da Universidade Federal do Rio Grande do Sul (UFRGS). Para isso, no decorrer do estudo avaliam-se (1) as estruturas da disciplina de RI que constrangem a ascensão de teorias distintas das mainstream; (2) as relações de poder e conhecimento entre Norte e Sul, que configuram um Centro e uma Periferia no âmbito acadêmico; (3) novos caminhos dentro da disciplina propostos pelas teorias pós-positivistas e reflexivistas (4) e, as principais formulações teóricas em RI da América Latina, mais especificamente do Brasil, através das universidades selecionadas. As conclusões prévias apresentadas são de que a maioria das teorizações nos casos estudados, dedica-se à construção ou redefinição de conceitos e/ou criação de modelos de análise, sendo os principais temas abordados por estas: Economia Internacional, Segurança Internacional e Política Externa. O que reflete avanços e limites das iniciativas de construção teórica no Sul Global.
\end{abstract}

PALAVRAS-CHAVE: Teoria de Relações Internacionais; Sul Global; Brasil.

\section{IR THEORIZATION PROCESS IN BRAZIL: AN ANALYSIS FROM PRODUCTIONS IN PUC-RJ AND UFRGS}

ABSTRACT: This research deals with the process of knowledge construction in International Relations (IR). It is directed to the analysis of the construction of International Relations Theory (IRT) in the Global South, and more specifically in Brazil in the 21st century. The main objective is to understand the theorizing process of IRT in the country through the analysis of doctoral theses elaborated in the area, from the Pontifical Catholic University of Rio de Janeiro (PUC-RJ) and the Federal University of Rio Grande do Sul (UFRGS). During the study, it is evaluated (1) the structures of IR that constrain the rise of different theories from the mainstream; (2) the relations of power and knowledge between North and South, which constitute a Center and a Periphery in the academic sphere; (3) new ways proposed by pos- positivist and reflexivist perspectives (4) the main IR theoretical formulations in Latin America, and more specifically in Brazil. The previous conclusions are that, in the cases analyzed, most theorizations are dedicated to the concepts construction or redefinition of and/or the creation of analysis models. The main themes addressed by these are: International Economics, International Security and Foreign Policy. This reflects advances and limitations of theoretical building initiatives in the Global South.

KEYWORDS: International Relation Theories; Global South; Brazil. 


\section{Introdução}

O artigo aborda Teoria de Relações Internacionais (TRI), mais especificamente as TRI construídas no Brasil no século XXI. Trata do processo de construção do conhecimento na disciplina e busca elucidar novas formas de pensar o internacional. A disciplina de Relações Internacionais (RI) é formada, majoritariamente por Teorias do Norte Global, as quais têm construído a disciplina com base no que consideram como conhecimento válido, dificultando assim, a ascensão de formas distintas de interpretar e construir o conhecimento. Esse contexto faz com que a realidade do Terceiro Mundo raramente apareça nos estudos de RI, muito menos as formulações dos países dessa região sobre o âmbito internacional. No entanto, no contexto da ascensão de críticas pós-positivistas e reflexivistas nos anos 1980, novas vozes têm conquistado espaço nas RI, e com elas a necessidade de reestruturação da própria disciplina.

Poucos trabalhos foram realizados na tentativa de compreender interpretações que os países do Sul Global, inclusive o Brasil, possuem das RI e as teorias que constroem nesta área. Além disso, a discussão dentro da disciplina sobre epistemologia é escassa, o que acaba por reforçar os conceitos e definições já consolidados no debate mainstream. Tendo em vista este déficit e a dificuldade de inclusão de teorias distintas das de matriz ocidental nas RI, esta pesquisa pretende analisar o processo de construção do conhecimento na área, tornando visível o que é construído de Teoria de Relações no Sul Global, com foco na América Latina e no Brasil, mais especificamente. Com o intuito de contribuir para a inclusão de novas formas de pensar as RI, esta pesquisa tem como foco as TRI construídas no Brasil no século $X X I$, a partir da análise do processo de teorização em RI na PUC-RJ e na UFRGS.

Ao avaliarmos os Programas de Pós-Graduação com doutorado em RI no Brasil percebemos que a maioria destes de concentram na região Sudeste, sendo que apenas quatro de um total de dez PPGs são localizados em outras regiões. Destes, destaca-se a Universidade de Brasília (UNB) na região Centro-Oeste, uma grande referência em estudos de RI no Brasil, é o PPG que possui o maior número de teses de doutorado na área, podendo também ser considerada um "Norte" da produção de conhecimento em RI no país em conjunto com o Sudeste. Além da 
Nordeste (UFBA), sendo os doutorados da UFSC e UFBA recém implementados.

Tabela 1 - Programas de doutorado em RI no Brasil ${ }^{1}$

\begin{tabular}{|c|c|c|}
\hline Universidade & Região & $\begin{array}{l}\text { Número de } \\
\text { teses } \\
\text { disponíveis }\end{array}$ \\
\hline Universidade Federal da Bahia (UFBA) & Nordeste & 0 \\
\hline Universidade de Brasília (UNB) & Centro-Oeste & 87 \\
\hline Universidade Federal de Santa Catarina (UFSC) & Sul & 0 \\
\hline $\begin{array}{l}\text { Universidade Federal do Rio Grande do Sul } \\
\text { (UFRGS) }\end{array}$ & Sul & $29^{2}$ \\
\hline Universidade de São Paulo (USP) & Sudeste & 47 \\
\hline Universidade do Estado do Rio de Janeiro (UERJ) & Sudeste & * \\
\hline $\begin{array}{l}\text { Pontifícia Universidade Católica de Minas Gerais } \\
\text { (PUC/MG) }\end{array}$ & Sudeste & 16 \\
\hline $\begin{array}{l}\text { PPGRI San Tiago Dantas (UNESP-UNICAMP-PUC- } \\
\text { SP) }\end{array}$ & Sudeste & 40 \\
\hline $\begin{array}{l}\text { Pontifícia Universidade Católica do Rio de Janeiro } \\
\text { (PUC-RIO) }\end{array}$ & Sudeste & 34 \\
\hline Universidade Federal Fluminense (UFF) & Sudeste & * \\
\hline Total & & 253 \\
\hline
\end{tabular}

Essa arquitetura desigual no que se refere a produção do conhecimento em RI no Brasil reflete a existência de hierarquias do saber e de dinâmicas de poder Norte/Sul dentro dos próprios estados nacionais, uma vez que as regiões que concentram a maior parte da produção científica do país é também onde se encontra a maior concentração de capital socioeconômico. Há, portanto, uma conexão desta relação com os fluxos transnacionais do próprio sistema capitalista, questão que abordaremos mais adiante.

\footnotetext{
1 Além dos PPGs com Programa de doutorado em Relações Internacionais foram considerados também os PPGs com doutorado em Estudos Estratégicos (UFRGS e UFF), pois entende-se esta área como um subcampo das RI.

${ }^{2}$ A partir da data da realização da análise das teses desta pesquisa (2016), novas teses foram defendidas e disponibilizadas nos sites dos PPGs, por isso o aumento do número.
} 
Compreendemos, deste modo, que apesar da diversidade de programas de pós-graduação em RI no país, o Brasil também apresenta um "Centro" ou "Norte" a nível nacional no que se refere a produção do conhecimento: o eixo Sudeste-Centro Oeste. Nele encontram-se os PPGs em RI mais antigos do país e, portanto, também o maior número de teses defendidas. Tendo em vista que não há programas de doutorado em RI na região Norte do Brasil, e apenas um na região Nordeste (UFBA), o qual foi estabelecido no ano de 2019, não apresentando, portanto, teses para serem analisadas, foi necessário um recorte dentro dos PPGs que continham material para a análise. Deste modo, dentre os PPGs com teses disponíveis optouse pela escolha da Pontifícia Universidade Católica do Rio de Janeiro (PUC-RJ), por ser a instituição onde entrou em funcionamento o primeiro programa de doutorado em RI do Brasil, e o PPG em Estudos Estratégicos Internacionais da Universidade Federal do Rio Grande do Sul (UFRGS), por ser a única universidade fora do eixo Sudeste-Centro Oeste a possuir teses disponíveis. Ademais, uma instituição é privada e outra pública, além de localizarem-se em regiões distintas, fatores que enriquecem o estudo. Ressaltamos que a análise da relação com demais programas localizados no "Sul" do país e suas teorizações é um passo importante para pesquisas futuras, pois certamente apresentaria novos dados à pesquisa, complexificando a avaliação da perspectiva brasileira sobre o internacional.

Para compreender o que é construído de TRI no Brasil a partir das produções em PUC-RJ e UFRGS no século XXI, foram analisadas todas as teses disponíveis de forma completa nas plataformas online das respectivas universidades, desde o início dos programas de doutorado, até o mês de outubro de 2016, quando foi desenvolvida a pesquisa. Assim sendo, contamos com dezoito teses da PUC-RJ e quinze da UFRGS. A pergunta que direciona a pesquisa é: o que é construído no processo de teorização em Relações Internacionais na PUC-RJ e na UFGRS no século XXI? Como objetivos específicos, busca-se (1) compreender o processo de construção do conhecimento em Relações internacionais (RI); (2) entender a estrutura que dificulta a ascensão de formas de teorizar distintas das ocidentais; (3) apresentar as principais TRI construídas na América Latina; e (4) avaliar a construção teórica em RI no Brasil no século XXI, a partir dos casos selecionados (PUC-RJ e UFRGS). A pesquisa é de caráter exploratório e descritivo e a técnica utilizada é bibliográfica. Faz-se uso essencialmente de métodos qualitativos, com amparo de dados quantitativos. 
Concluímos que no Brasil no século XXI as teorizações em RI, nos casos selecionados, tratam principalmente de temas de Economia Internacional, Segurança Internacional e Política Externa e o nível de análise preponderante é o da unidade. A maioria das formulações dedica-se à construção ou redefinição de conceitos e/ou criação de modelos de análise. Há grande diálogo com Teorias de Norte, no entanto, as Teorias do Sul aparecem presentes em um grande número de teses, sendo alto o percentual das que dialogam com ambas regiões. Observa-se também o aumento do diálogo com teorias pós-positivistas e reflexivistas e da abordagem de temas distintos dos mainstream. Tais características evidenciam avanços e limites das iniciativas de construção teórica no Sul Global. No primeiro caso, percebe-se a ampliação de perspectivas epistemológicas ecléticas e adoção de metodologias reflexivistas e críticas. No âmbito dos limites, observa-se a dificuldade de proposição de corpos teóricos próprios, de perspectivas sistêmicas e de iniciativas teóricas explicativas, o que limita a amplitude e pluralidade das teorias produzidas no Sul.

O presente estudo é organizado em três seções. Na primeira, propomos um debate acerca das noções sobre ciência e teoria; apresentamos o desenvolvimento de uma estrutura Centro/Periferia no que se refere a construção e absorção do conhecimento em RI; analisamos, a partir da sociologia da ciência, os principais constrangimentos à construção de TRI no Sul; e apresentamos as respostas do Sul a este contexto. Na segunda seção, apresentamos as principais construções teóricas em RI da América Latina e refletimos sobre a interiorização de um "complexo de vira-lata" intelectual na região acerca do papel e validade das teorias locais. Por fim, apresentamos a análise das teorias construídas no Brasil dos anos 2000 até a atualidade, nos casos selecionados (PPGRI da PUC-RJ e PPGEEI da UFRGS).

\section{Ciência, Teoria e Relações Internacionais}

As Relações internacionais (RI) surgem como ciência no século $X X$, quando a necessidade de pensar $o$ internacional se torna mais evidente devido às consequências das duas Grandes Guerras e as configurações da Guerra Fria. Essa noção de ciência que abarca as RI e outras áreas de construção do conhecimento 
possui um prestígio cultural na sociedade, e, por isso, quando a invocamos logo aparecem conectadas a ela, noções de "progresso" e "verdade" (JACKSON, 2011). Deste modo, a noção de ciência se constrói como um conceito impreciso, confuso, mas com grande poder de autorreferenciação, ou seja, se estabelece de maneira imediata uma confiança naquilo que é designado como científico (CAMPOS, 2014). O poder retórico da noção de ciência faz com que esta seja vista como uma forma superior de construir e qualificar o conhecimento. Deste modo, algumas maneiras de fazer pesquisa são privilegiadas enquanto outras são marginalizadas. Assim, "caracterizar uma pesquisa como não científica "carrega conotações imensamente negativas"3 (JACKSON, 2011, p.9). A ciência nas RI camufla-se sob o rótulo da "teoria" e exerce uma função disciplinadora, ou seja, tem o poder de decidir o que é considerado válido ou não dentro desta área do conhecimento (CAMPOS, 2014; KURKI; WIGHT, 2013, p. 32). Teorias são abstrações da realidade, tentativas de interpretar o mundo, o ser humano, o ambiente. Lentes através das quais interpretamos a realidade. De maneira mais ampla, e abrangendo as duas definições acima, teorias são abstrações feitas a partir de acontecimentos do nosso cotidiano, no qual procuramos encontrar padrões, agrupar eventos e classificar coisas. Isso ocorre na medida em que percebemos as similaridades e as singularidades dos acontecimentos, os quais "têm tanto algumas características únicas quanto algumas que compartilha com outros eventos similares"4 (ACHARYA;BUZAN, 2010, p. 4). Por meio de um olhar crítico acerca destas definições, reconhecemos, assim como Arlene Tickner e Ole Wæver (2010), a necessidade de "expandir as fronteiras das Relações Internacionais, buscando uma discussão mais aberta sobre definições" (TICKNER; WAEVER, 2010, p.17).

As RI são um campo de estudo complexo, que se estrutura de forma multidisciplinar para a tarefa de analisar o internacional sob os mais distintos ângulos (PECEQUILO, 2004). Por isso, é formada por um grande número de vertentes teóricas que apresentam instrumentos diferentes para a análise da realidade internacional. Todas as formulações teóricas possuem considerações particulares com relação à ontologia (o ser: o que estudar?), epistemologia (o conhecimento: que conhecimento é válido?) e metodologia (os métodos: que métodos utilizar para

\footnotetext{
3 "carries immensely negative connotations" (JACKSON, 2011, p.9).

4 "will have both some unique features and some that it shares with others of its type" (ACHARYA E BUZAN, 2010, p. 4).
} 
chegar ao conhecimento?). Sendo assim, cada teórica (o) possui uma lente própria pela qual enxerga o mundo (KURKI; WIGHT, 2013). Teorias são abstrações da realidade, tentativas de interpretar o mundo, o ser humano, o ambiente. $O$ conhecimento move a sociedade, a estrutura e a modifica. No entanto, ao mesmo passo em que grandes teorias vão construindo nossa compreensão da realidade ao longo do tempo, outros conhecimentos e interpretações vão sendo ocultadas da história. Isso ocorre porque toda teoria é construída sob a influência de questões políticas, sociais, econômicas e culturais - entre outros fatores- que envolvem a (0) teórica (o) e o seu local de enunciação. Ou seja, todas as teorias "derivam de um determinado tempo e espaço" e são "sempre para alguém e com algum propósito" (COX, 1996, p. 207).

Nas Relações Internacionais, o debate e a construção de teorias são, majoritariamente, realizados no Norte Global, principalmente nos Estados Unidos. Por isso, a própria disciplina é muitas vezes intitulada como "uma ciência social estadunidense"5 (HOFFMAN, 1977). As teorias mainstream de RI "são essencialmente teorias eurocêntricas, originadas, em grande parte nos EUA e fundadas, quase exclusivamente, no que acontece ou aconteceu no Ocidente" (NEUMAN, 1998, p. 2). Enquanto a realidade do Sul permanece pouco estudada na disciplina. Deste modo, "o estudo das Relações Internacionais é conduzido principalmente a partir de um espaço geopolítico específico (EUA), que passa a ser o país mais poderoso tanto no contexto internacional quanto na disciplina"6 (TICKNER;WAEVER, 2009, p. 5). Esse contexto configura um "Centro" e uma "Periferia" no que diz respeito à construção do conhecimento em RI (TICKNER, 2009 , 2013). Enquanto os primeiros são aqueles que estruturam as principais teorias e definem o que é válido como conhecimento na área, aos segundos cabe a função de fornecimento de dados às pesquisas. O funcionamento do Sistema CentroPeriferia ocorre por meio da diferença colonial e geopolítica do conhecimento, conceitos desenvolvidos por Walter Mignolo. A diferença colonial refere-se à hierarquização de saberes, ou seja, a ideia de que o Ocidente é o ponto máximo da evolução, enquanto os demais povos são vistos como inferiores. Já a geopolítica do conhecimento "é a relação entre espaços (geográfica e historicamente constituídos)

\footnotetext{
5 "an American Social Science" (HOFFMAN, 1997).

6 "the study of international relations is conducted primarily from a specific geopolitical site (the United States) that happens to be the most powerful country in both international affairs and the discipline itself" (TICKNER; WAEVER, 2009, p. 5).
} 
e pensamento" (MIGNOLO, 2002, p. 66). Ou seja, o local onde a teoria é construída determina seu alcance, sua importância e validade.

Para que possamos entender como se estrutura esse domínio do Ocidente é preciso analisar as condições sob as quais o conhecimento em RI é produzido nos diferentes cantos do mundo. Para isso, através da sociologia da ciência, que se preocupa em analisar as variáveis que compõem o ambiente social no qual as (os) pesquisadoras (es) estão inseridas (os), podemos elencar os principais fatores que contribuem para as disparidades nas relações Norte/Sul. São eles: o legado do imperialismo ocidental (ACHARYA; BUZAN, 2011), a questão da língua; o poder de revistas e jornais de maior visibilidade na disciplina, a demanda e recursos locais; e a atuação de fundações filantrópicas no Sul (TICKNER, 2013). O impacto, presente até os dias de hoje, do imperialismo ocidental, impacta fortemente as teorizações no Sul, pois esse fenômeno não só "subjugou as tradições locais de pensamento e conhecimento, mas também desconectou esses povos de sua própria história, delineando a sua auto compreensão dentro de um marco histórico ocidental"7 (ACHARYA; BUZAN, 2011, p.18). O estabelecimento do inglês, como língua "oficial" da disciplina, uma vez que é a língua nativa dos EUA e Inglaterra. Esse fato exige maiores esforços de estudiosas (os) de outros lugares para entender e escrever em um idioma diferente. Além disso, os jornais e revistas de maior visibilidade na área (situados no Norte) possuem grande poder sobre que temas, assuntos e pesquisas circulam no meio acadêmico (TICKNER, 2013). As condições locais também são um fator de influência nas disparidades Norte/Sul. Pouco investimento em educação, falta de estrutura material e financeira para a realização de pesquisas, além do legado colonial de "guerra, instabilidade crônica, insegurança e pobreza aguda" impactam "as maneiras pelas quais a realidade é refletida e problematizada"8 (TICKNER, 2003, p. 307). As fundações filantrópicas, por sua vez, influenciam as pesquisas no Sul por meio do desenvolvimento de "centros de excelência", com os quais estabelecem ligações e estimulam investigações em áreas específicas (TICKNER, 2013).

\footnotetext{
7 "overwhelmed local traditions of thought and knowledge, but also cut peoples off from their own history by drawing their self-understanding into a Western historical frame" (ACHARYA; BUZAN, 2011, p.18).

8 "a colonial legacy, war, chronic instability and insecurity, and acute poverty form part of their concrete working conditions, the ways in which reality is reflected upon and problematized is no doubt influenced by the intrusive nature of everyday life" (TICKNER, 2003, p. 307).
} 
A periferia, por sua vez, responde de diferentes maneiras à estrutura CentroPeriferia das RI, a qual restringe sua ação no processo de construção do conhecimento na disciplina. Arlene Tickner (2013) aponta três atitudes como as mais comuns: 1) "Adaptação/enquadramento" (fitting in); 2) "dominação por convite", e 3) “desvinculação". Segundo Tickner (2013), a primeira reação é a que ocorre com maior frequência, na qual as (os) autoras (es) do Sul aceitam implícita ou explicitamente a existência do centro e buscam posicionarem-se de uma maneira favorável com relação a isso. No caso da América Latina como um todo, e do Brasil mais especificamente, podemos perceber que as três reações se fazem presentes. Apesar de grande adesão às duas primeiras (adaptação e "dominação por convite") podemos perceber o crescimento de formulações fora do eixo mainstream e a incorporação cada vez maior da crítica reflexivista na região.

A crítica pós-positivista ${ }^{9}$ ou reflexivista direciona-se aos pressupostos essenciais do positivismo. De maneira mais específica, as teóricas (os) reflexivistas discordam do entendimento de que é possível separar o sujeito que pesquisa do objeto pesquisado, ou seja, que existe um mundo "lá fora" independentemente do que sabemos sobre ele. No entanto, ao questionarem premissas epistemológicas, ontológicas e metodológicas sob as quais as mais famosas TRI se estruturam têm sofrido para que suas formulações sejam levadas a sério (KURKI; WIGHT, 2013). Em um escopo mais amplo, dentro das Ciências Sociais, esse movimento vem sendo acompanhado pela crítica pós-colonial. As chamadas Epistemologias do Sul, ou Teorias do Sul, "denunciam a supressão dos saberes levada a cabo, ao longo dos últimos séculos, pela norma epistemológica dominante, valorizam os saberes que resistiram com êxito e as reflexões que estes têm produzido e investigam as condições de um diálogo horizontal entre conhecimentos" (SANTOS;MENEZES, 2009, p.7).

Dentro deste arcabouço teórico destacam-se os estudos pós-coloniais e decoloniais. Estes têm se tornado importantes instrumentos para a análise das relações de poder entre Norte e Sul e inspirado maiores reflexões dentro da

\footnotetext{
${ }^{9}$ Essas abordagens surgem com maior força a partir dos anos 1980 (no contexto do chamado "quarto debate") trazendo "questionamentos à linguagem, aos conceitos, aos métodos, e a própria história (ou discurso dominante)" (JATOBÁ, 2013, p.100) das Relações Internacionais. Entre as principais abordagens que compõem esse grupo estão: Pós-Estruturalismo, Teoria Crítica, Construtivismo, PósModernismo, Teorias Feministas e Pós-Colonialismo. Essas teorias "representam um ataque massivo às teorias tradicionais (mainstream) de Relações Internacionais, as quais têm sido dominadas por premissas positivistas" (SMITH, 1996, p. 12).
} 
disciplina de RI. Um elemento central à análise pós-colonial e decolonial é o processo de construção do conhecimento, uma vez que tais perspectivas direcionam "sua crítica contra a hegemonia cultural dos saberes europeus, numa tentativa de reafirmar o valor epistemológico e a agência do mundo não-europeu"10 (GANDHI, 1998, p. 44). Assim, importantes reflexões acerca das relações de poder entre Norte e Sul no que se refere ao processo de construção do conhecimento são trazidas pelas chamadas Teorias do Sul.

O que hoje metaforicamente se chama de Sul Global possui também outras conotações, entre as quais, estão o conceito de Terceiro Mundo e o de Periferia. A Conferência de Bandung, em 1955, foi o marco simbólico da construção do Terceiro Mundo. Depois de Bandung várias outras conferências resultaram em alianças político-ideológicas e na formação de uma identidade comum entre esse grupo de países, pois possuíam preocupações comuns tanto no âmbito interno quanto no externo, tais como a desigualdade social e a condição subjugada em que se encontram na economia mundial. Com o fim da Guerra Fria o conceito de Terceiro Mundo passa gradualmente a cair em desuso. No entanto, como destaca Mohammed Ayoob, o conceito de Terceiro Mundo "tem fronteiras flexíveis ao invés de fronteiras rígidas" (1995, p. 13). Deste modo, a emergência de outros conceitos para designar esta parte do mundo não demonstra uma ruptura com o significado do termo, mas um ampliamento deste. Atualmente, a configuração dos Não-Alinhados que se originou em Bandung não existe mais, porém "a cartografia imaginária que justificou o Terceiro Mundo ainda existe" (GROVOGUI, 2011, p. 178). E, por isso, o conceito de Sul Global, que passa a ser mais utilizado, "capta o espírito engajado do Terceiro Mundo e continua nos convidando para um reexame dos fundamentos intelectuais, políticos e morais do sistema internacional" (GROVOGUI, 2011, p. 175). Este convite é feito também pelo conceito de periferia ${ }^{11}$, que, elaborado por autores da Teoria do Sistema Mundo e da Teoria da Dependência, chama atenção para o caráter hierárquico e desigual do Sistema Internacional.

\footnotetext{
10 "a disciplinary project devoted to the academic task of revisiting, remembering and, crucially, interrogating the colonial past" (GANDHI, 1998, p.4).

${ }^{11}$ Para os fins deste estudo os termos Sul Global, Terceiro Mundo, e Periferia serão utilizados como sinônimos. Considerou-se necessária a utilização destes, uma vez que são os conceitos que possuem maior alcance no âmbito acadêmico e foram os que trouxeram visibilidade à discussão sobre a parte menos privilegiada do globo. No entanto, devemos "continuar problematizando seu significado, validade, aplicabilidade, etc., mantendo um espaço aberto para a possibilidade de novas categorias" (SLATER, 2008, p. 10).
} 
Um dos fatores de identificação entre muitos destes países é o compartilhamento de um passado colonial. Arlif Dirlik (2005) destaca, no entanto, que a luta contra o colonialismo e as hierarquias geradas por este tem sido direcionada, mais recentemente, contra opressões advindas da formação de uma estrutura globalizante a partir da expansão do capitalismo. Nesse contexto ocorre a "universalização das contradições de uma modernidade capitalista, não apenas entre sociedades, mas, mais importante, dentro delas" (DIRLIK, 2005, p.7). Ou seja, a compreensão da modernidade colonial é central para visualizar as hierarquias de poder que moldam o mundo atualmente, mas o pilar de sustentação dessa estrutura torna-se a transnacionalização do capitalismo. Esse processo faz do colonialismo não um evento findado na modernidade, mas uma característica da vida cotidiana. Dirlik (2005) chama atenção para a complexidade das relações de poder a nível nacional e internacional, demonstrando que o encontro colonial entre o "mundo civilizado" e "os bárbaros" produz não apenas dicotomias globais entre um Norte e um Sul, mas também a produção de colonialismos internos, dentro do escopo dos estados nacionais. Podemos perceber essa realidade ao analisarmos a disposição dos programas de pós-graduação em RI no Brasil, em que algumas regiões do país (Sudeste-Centro Oeste) concentram a maior parte dos programas de doutorado na área, caracterizando-se como um "Centro" ou "Norte" a nível nacional.

\section{América Latina e Teoria de Relações Internacionais}

A crítica pós-colonial carrega em seus fundamentos a valorização da produção teórica em regiões periféricas. Na América Latina, especificamente, a produção teórica em Relações Internacionais foi avaliada de forma mais ampla pelo argentino Raúl Bernal-Meza, em América Latina en el Mundo: El pensamiento latinoamericano y la teoría de relaciones internacionales (2005). Na obra, o autor estabelece uma sistematização da produção teórica própria da América Latina. Segundo o autor, a partir de teorias que compartilharam de premissas comuns, foi possível o desenvolvimento de uma "Escola" ou "Tradição de pensamento" latinoamericana de Relações Internacionais: o estruturalismo. A principal característica dessa perspectiva "tem sido seu enfoque macro histórico e sistêmico, que passou a ser predominante nas ciências sociais da região por sua originalidade e 
contribuições"12 (BERNAL-MEZA, 2005, p.24). As formulações da Escola Estruturalista têm como principal tema o estudo do desenvolvimento histórico do capitalismo e, por meio desse, demonstram a estrutura desigual pela qual o Sistema Internacional se estabelece, caracterizado por um Centro e uma Periferia.

Segundo Bernal-Meza o estruturalismo latino americano pode ser compreendido em três momentos: 1) a Teoria original de Prebish; 2) as modificações e contribuições feitas pela Teoria do Desenvolvimento (Celso Furtado) e enfoques da Dependência (Fernando Henrique Cardoso, Henzo Falleto, Theotônio dos Santos, Maria da Conceição Tavares, Ruy Mauro Marini e Vania Bambirra); e 3) o Neoestruturalismo (Luciano Tomassini, Aldo Ferrer, Osvaldo Sunkel, Mario Rapoport e Raúl Bernal-Meza). As três formulações analisam o desenvolvimento histórico do Sistema Capitalista, e constituem, por sua vez, "um grande relato histórico desde a periferia" (BERNAL-MEZA, 2005, p. 29). Posteriormente, surgem os enfoques da Autonomia, desenvolvidos por Hélio Jaguaribe, Carlos Puig, Guillermo O'Donnell e Delfina Link, Roberto Russell e Juan Gabriel Tokatlián. Estes (a) autores buscam avaliar o significado da autonomia para os países latino americanos, e os caminhos e dificuldades para alcançá-la.

No que se refere às contribuições brasileiras em RI, há escassa produção que sistematize as contribuições teóricas desenvolvidas no país. Com base na literatura disponível, verificamos que até os anos 2000, os principais avanços teóricos surgem majoritariamente por meio de análises voltadas à Economia Política Internacional (EPI). Podemos definir a EPI como "um desdobramento da economia política [que] possui, tradicionalmente, um caráter multidisciplinar, combinando análises da dinâmica do capitalismo, das relações de poder no sistema internacional, do desenvolvimento dos Estados" (BARASUOL, 2012, p. 1). A principal referência nesse caso é a Teoria da Dependência, esta por sua vez, influencia nas formulações sobre o tema da autonomia, no qual destaca-se a relevância do autor brasileiro Hélio Jaguaribe.

Outras teorizações brasileiras importantes e difundidas são de: Araújo Castro, através do entendimento da relação entre as duas superpotências pelo conceito de "congelamento do poder mundial", que inaugura análises voltadas para o Sistema Internacional (HERZ, 2002); de Golbery do Couto e Silva e Carlos de Meira Matos,

12 "ha sido su enfoque macro-histórico y sistémico, que pasó a ser predominante en las ciencias sociales por su originalidad y aportes" (BERNAL-MEZA, 2005, p.24). 
sobre a estrutura do Sistema Internacional e a geopolítica regional; de Maria Regina Soares de Lima e sua análise da política externa dos países periféricos a partir da abordagem da ação coletiva (HERZ, 2002); de Celso Lafer e a compreensão da política externa brasileira a partir das identidades do país; de Gelson Fonseca e a utilização dos conceitos de "autonomia pela distância" e "autonomia pela participação" para a análise de PE; de Tullo Vigevani e Gabriel Cepaluni e o conceito de "autonomia pela diversificação"; de Samuel Pinheiro Guimarães e o conceito de "Grandes Estados Periféricos" que está relacionado ao conceito de "Potência Regional" desenvolvido por Maria Regina Soares de Lima (2005); de Amado Cervo e sua interpretação centrada na elaboração de "paradigmas" e conceitos de Política Externa; de Paulo Fagundes Vizentini sobre o contexto internacional Pós-Guerra Fria, o qual denomina (des)ordem mundial; de Gerson Moura acerca da autonomia na dependência; de Renato Ortiz e de Otávio lanni sobre o tema da globalização (HERZ, 2002); de Maria da Conceição Tavares, em seu estudo sobre A Retomada da Hegemonia Norte-americana (1997), e em sua análise sobre a economia política da globalização, em conjunto com José Luís Fiori; e de Theotônio dos Santos e seu entendimento estruturalista acerca da economia mundial.

Contudo, a despeito da quantidade e relevância dessas e de outras teorizações, as inúmeras relações de poder que envolvem a produção e difusão do conhecimento na disciplina fazem com que as construções teóricas da periferia permaneçam, na grande maioria das vezes, silenciadas e subvalorizadas. Isso decorre da visão predominante na disciplina, que pressupõe as teorias construídas na periferia como "não científicas" e inferiores ao que é produzido no Norte. Essa visão é reflexo da estrutura centro-periferia da produção intelectual, na qual criou-se "um circuito fechado que aprisionava a reflexão dotada de sistematicidade, originalidade e profundidade nos limites dos países "cêntricos", excluindo a possibilidade de sua existência na periferia" (LYNCH, p.737). Deste modo, as formulações ocidentais são as que carregam o título de teoria, sendo reconhecidas como "coerentes, abrangentes e abstratas" e com validade universal, enquanto as construções da periferia, ao serem caracterizadas como "fragmentárias, contingentes ou assistemáticas" e com alcance nacional, não sendo dotadas, portanto, da mesma precisão científica, carregam o título de pensamento. (LYNCH, 2013, p.733). 
Esta compreensão de 'teoria' como superior a 'pensamento', reflexo do sistema Centro-Periferia no campo do saber, impõe um molde de como teorizar, descartando variações que não se adequem ao que é considerado como sistemático, abrangente e universal. A pressão para se enquadrar nos moldes ocidentais constrange o processo de teorização de pesquisadores (as) de países periféricos, uma vez que suas produções dificilmente entram nos círculos acadêmicos cêntricos, que aliado ao escasso debate sobre o processo de produção do conhecimento no âmbito interno, podem levar a interiorização de uma ideia de inferioridade perante teorizações ocidentais. Assim, a incorporação de um "colonialismo intelectual" torna-se visível quando, na periferia, ocorre "o emprego da palavra "pensamento" no lugar de "teoria", para designar os seus produtos intelectuais, [a qual] parece já embutir o reconhecimento da sua inferioridade" (LYNCH, 2013, p. 759). Como destaca Luciana Ballestrin (2014), "do ponto de vista da geopolítica do conhecimento e da divisão global do trabalho acadêmico, a categoria "pensamento" é problemática, revelando em si mesma um aspecto de colonialismo intelectual" (p.4). Por outro lado, a percepção da necessidade de transcender esse "colonialismo intelectual" conduziu muitos autores(as) latinoamericanos à busca de uma identidade independente no campo da ciência durante o século $X X$. A América Latina é palco de inúmeras reflexões sobre temas como colonialismo, racismo e escravidão além de questões referentes ao desenvolvimento, cooperação, autonomia, entre outros, e merece ter suas formulações reconhecidas (BALLESTRIN, 2014; QUIJANO, 2005; CARDOSO; FALLETO, 1975).

\section{Teorizações Brasileiras em RI no século XXI}

Nesta seção será apresentada a análise sobre as TRI construídas na PUC-RJ e na UFRGS a partir dos anos 2000. Como fonte para identificar a construção de teorias de RI no país serão avaliadas as teses dos programas de doutorado em RI da Pontifícia Universidade Católica do Rio de Janeiro (PUC-RJ) e da Universidade Federal do Rio Grande do Sul (UFRGS). Foram analisadas todas as teses disponíveis em sua totalidade das duas universidades desde o início de seus programas de doutorado até o mês de outubro de 2016 quando a análise foi 
desenvolvida. Deste modo, contamos com dezoito teses da PUC-RJ e quinze da UFRGS.

A análise se desenvolveu a partir da leitura do resumo, introdução, conclusão e, quando necessário, do capítulo teórico das teses. A análise foi conduzida por meio de três dimensões principais: 1) características gerais da tese; 2) perfil das(os) autoras(es); e 3) relação do trabalho com teoria. Dentro de cada dimensão foram avaliados os seguintes pontos: 1) características gerais da tese (tema; objeto/local que analisa; nível de análise, sendo unidade, regional, interregional ou sistêmico); 2) perfil das(os) autoras(es) (formação dos(as) autores(as) e gênero dos(as) autores(as) e orientadores(as); e 3) relação do trabalho com teoria, na qual avaliamos o diálogo com teorias de RI e de outras disciplinas; a posição geopolítica destas (Norte e ou Sul); a maneira como ocorre esse diálogo; e se há uma tentativa de criação de conceitos, operacionalização ou redefinição de conceitos. Analisamos também, nesse tópico, se alguma tese propôs a criação de modelos de análise ou caracteriza-se como explicação causal.

Por meio da avaliação destes tópicos podemos ter uma visão inicial acerca das teorizações em RI no Brasil. Constatamos no tópico 'temas' a prevalência na UFRGS daqueles considerados "tradicionais" dentro da disciplina. Nesta universidade, $40 \%$ das teses tratavam sobre Desenvolvimento e Economia Internacional, 26,7\% Política Externa e 20\% de Segurança Internacional (20\%). Na PUC-RJ, a Segurança Internacional é o tema prevalecente $(38,9 \%)$, seguido também pela Política Externa (16,7\%). Entretanto, nesta universidade podemos destacar a presença dos novos temas das RI como Meio Ambiente, Migrações, Gênero e Cultura, que juntas compõem $22,4 \%$ das teses. No que se refere aos objetos/locais analisados pelas teses, percebemos o predomínio do Brasil em ambas as universidades, característica já presente no decorrer do desenvolvimento da disciplina no país. Na UFRGS, logo após o Brasil (40\%) aparecem como locais mais estudados a África (20\%), seguida pela América Latina (13,3\%) e Ásia (13,3\%). É interessante notarmos a predominância de locais do Sul Global ou países emergentes nas análises desta universidade, que no total compõe 93,3\% das teses. Já na PUC-RJ, o Brasil (22,2\%), o Sistema Internacional (16,7\%), ONU $(16,7 \%)$ e Europa $(16,7 \%)$ surgem como locais mais estudados, seguidos pela América Latina $(11,1 \%)$. Nessas pesquisas o nível de análise que prevalece em ambas as universidades é o da unidade, $46,7 \%$ das teses da UFRGS estudam o nível unitário, 
$26,7 \%$ o nível regional e $26,7 \%$ o sistêmico. Na PUC-RJ o nível da unidade aparece em $61,1 \%$ das teses, o nível sistêmico em $27,8 \%$, o regional em $5,6 \%$ e o interregional nos outros $5,6 \%$. Portanto, em relação às temáticas e objetos, os estudos desenvolvidos no PPGEEI UFRGS mantêm foco em estudos do Sul global, com menor dedicação a abordagens limitadas ao nível de análise das unidades em comparação com o PPGRI PUC-RJ. Por outro lado, este último, amplia a abordagem de temas para além das temáticas tradicionais, predominantes no PPGEEI UFRGS.

Além das características gerais de cada tese faz-se necessário compreender o perfil de quem escreve, uma vez que não somos neutros e o que nos constrói enquanto seres humanos tem influência naquilo que estudamos. Portanto, por meio da avaliação do currículo Lattes das(os) autoras(es) e de suas descrições nas teses foi possível compreender como é a formação acadêmica dos(as) pesquisadores(as) de RI nestas universidades e também o gênero com o qual se identificam. É notável que a formação em RI das(os) doutoras(es) da UFRGS aparece na maioria dos casos apenas no doutoramento $(60 \%)$, seguido por formação no mestrado e doutorado $(26,7 \%)$, graduação e doutorado $(6,7 \%)$ e as três formações em RI (6,7\%). Na PUC-RJ a formação em RI no mestrado e doutorado aparece com maior porcentagem (55,6\%), seguida por apenas o doutorado (33,3\%) e as três formações $(11,1 \%)$. Esse fato elucida a predominância ainda no país, de doutoras(es) em RI não possuírem toda sua formação nessa área em específico, o que tende a mudar na medida em que a disciplina vem se consolidando no país e aumentam o número de cursos de graduação e pós-graduação, assim como o de profissionais da área. Mediante a descrição das(os) doutoras(es) na plataforma Lattes foi possível também verificar se estas(es) realizaram alguma etapa de sua formação acadêmica em países do Norte. Podemos perceber que a maioria $(66,7 \%)$ tanto na UFRGS quanto na PUC-RJ realizou sua formação completa no Sul. No entanto, é grande o percentual daquelas (es) que exerceram alguma etapa de sua formação no Norte (33,3\% em ambas). Com relação ao gênero foi possível confirmar o fato já debatido muitas vezes na disciplina, da predominância do gênero masculino em níveis mais avançados da academia como o doutorado. Na UFRGS 93,3\% das teses analisadas nesta pesquisa foram escritas por homens enquanto na PUC-RJ a porcentagem é um pouco menor, $75 \%$. No caso do gênero das(os) orientadoras (es) ocorre o mesmo, podemos visualizar novamente o predomínio do gênero masculino em 
ambas universidades, $77,8 \%$ na UFRGS e 75\% na PUC-RJ. ${ }^{13}$ Da análise da segunda dimensão, observa-se a recorrência de doutores(as) de formação mais diversa e multidisciplinar no PPGEEI UFRGS, mas com expressivo predomínio do gênero masculino, ao contrário da maior diversidade de gênero existente no PPGRI PUC-RJ.

A terceira dimensão analisada refere-se à relação que as teses estabelecem com a teoria da RI. Para compreendermos essa relação, elaboramos categorização a partir de uma escala de cinco níveis: 1) não utiliza; 2) utiliza de forma acessória; 3) utiliza no centro da análise; 4) utiliza no centro da análise e cria/redefine conceitos ou cria modelos de análise; e 5) utiliza para a construção de explicações causais. Por meio da leitura das teses foi possível perceber o predomínio do nível quatro (4) tanto na UFRGS quanto na PUC-RJ. Na UFRGS, predominam, na sequência, esses que utilizam teoria de forma acessória (2) e que utilizam teoria no centro da análise (3). O mesmo ocorre na PUC-RJ. Ainda que existam teses que não explicitam o uso de teorias e também de teses que as utilizam de forma acessória, a porcentagem que atribui às teorias um papel central no desenvolvimento do estudo e que procura desenvolver a criação/redefinição de conceitos, criação de modelos de análise ou o estabelecimento de explicações causais é grande. Isto demonstra que por mais que ao Sul seja delegada a tarefa de consumir o que é produzido no Norte, ao passo em que a disciplina de RI se estrutura no país cresce a atenção dada às teorias e ao processo de teorizar. Podemos visualizar nos gráficos abaixo como se configura a relação das teses com teoria em cada uma das universidades.

\footnotetext{
${ }^{13}$ Para pesquisas futuras seria interessante a realização da avaliação de gênero novamente, para que se possa averiguar se houve uma incorporação maior de mulheres na disciplina ou se esta permanecerá conduzida, majoritariamente por homens. Assim como a análise das condições econômicas e sociais, da orientação sexual e da identificação racial também constituiriam elementos importantes para o entendimento das RI no Brasil e merecem aprofundamento em pesquisas futuras.
} 


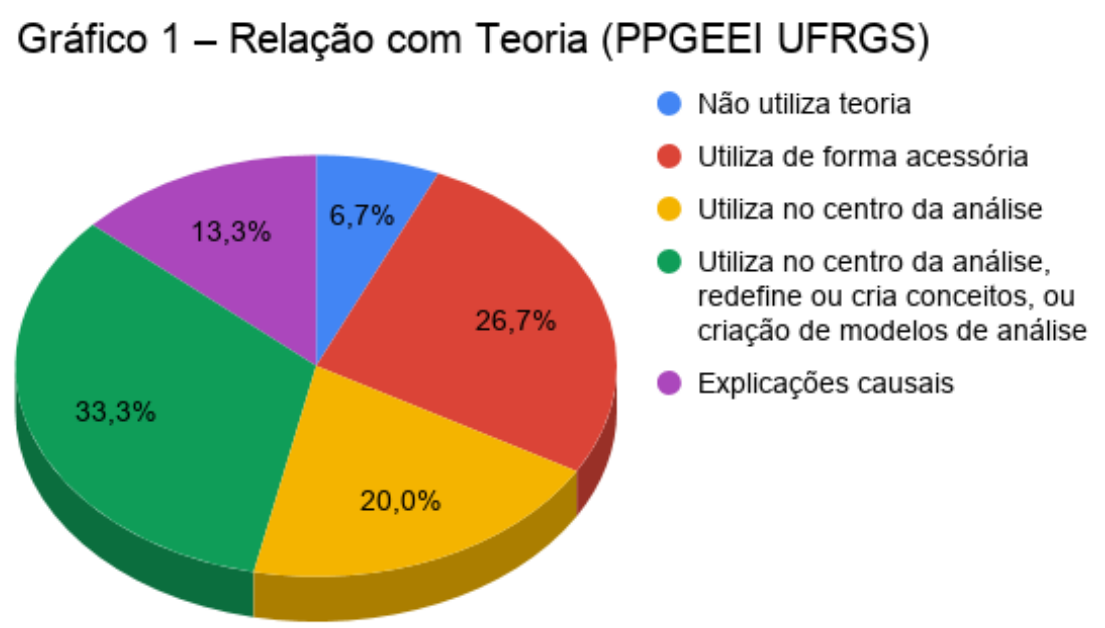

Fonte: Elaboração dos autores.

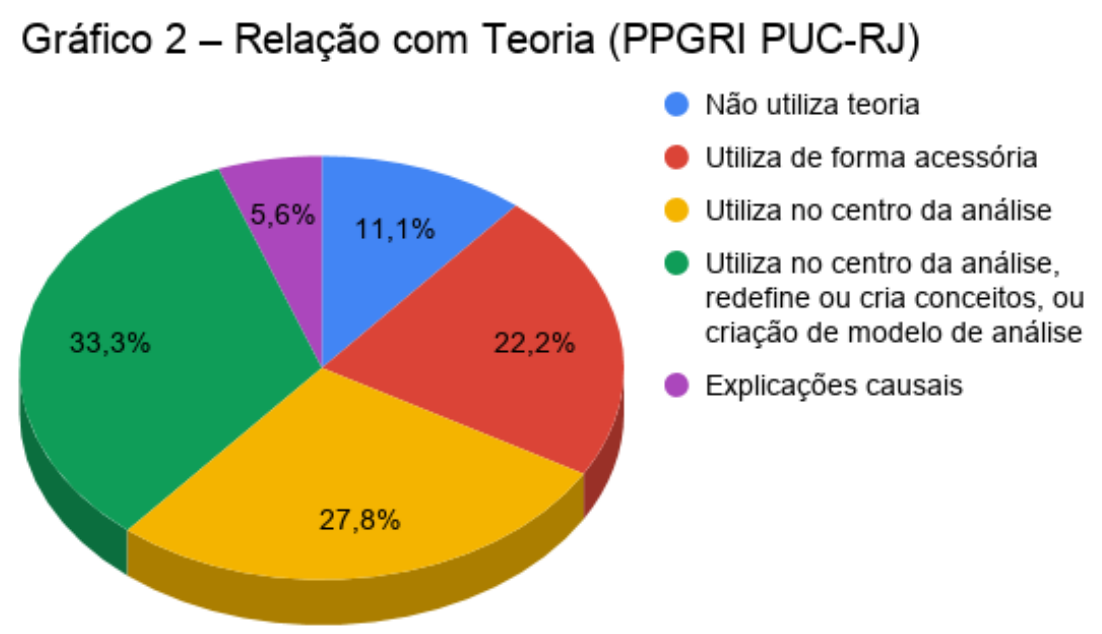

Fonte: Elaboração dos autores.

A relação com teoria também se compõe pela influência teórica geográfica. Para verificar esse ponto avaliamos o diálogo das teses com teorias do Norte, do Sul ou das duas localizações. Foi possível perceber um viés distinto em cada universidade com relação a este ponto. Enquanto na UFRGS predominam teses que se utilizam de teorias tanto do Norte quanto do Sul $(51,1 \%)$, seguida pelo diálogo apenas com teorias do Norte $(35,7 \%)$ e possui teses que apresentam teorias do Sul como principal referência $(7,1 \%)$, na PUC-RJ predomina o diálogo com teorias do Norte, que está em $81,3 \%$ das teses seguido pelo diálogo com teorias do Norte e Sul $(18,8 \%)$, sem apresentar teses que utilizem de forma principal teorias do Sul. Esses diálogos teóricos possuem influência de diversas disciplinas, percebemos 0 predomínio da utilização apenas de TRI na PUC-RJ (72,2\% das teses), enquanto na UFRGS a utilização de teorias de RI (26,7\%); e de RI e Economia (26,7\%) alcançam 
a maior porcentagem. É possível visualizar, a partir dos gráficos elaborados, como as teses de Relações Internacionais de ambas as universidades possuem um grande diálogo com outras disciplinas, principalmente a Economia e a Sociologia. Não obstante, na avaliação da influência teórica geográfica e disciplinar, o PPGEEI UFRGS destaca-se em relação ao PPGRI PUC-RJ pela ampliação do enfoque teórico para o uso de teorias do Sul e por receber mais influências de outras disciplinas.

Gráfico 3- Influência teórica disciplina (PPGEEI UFRGS)

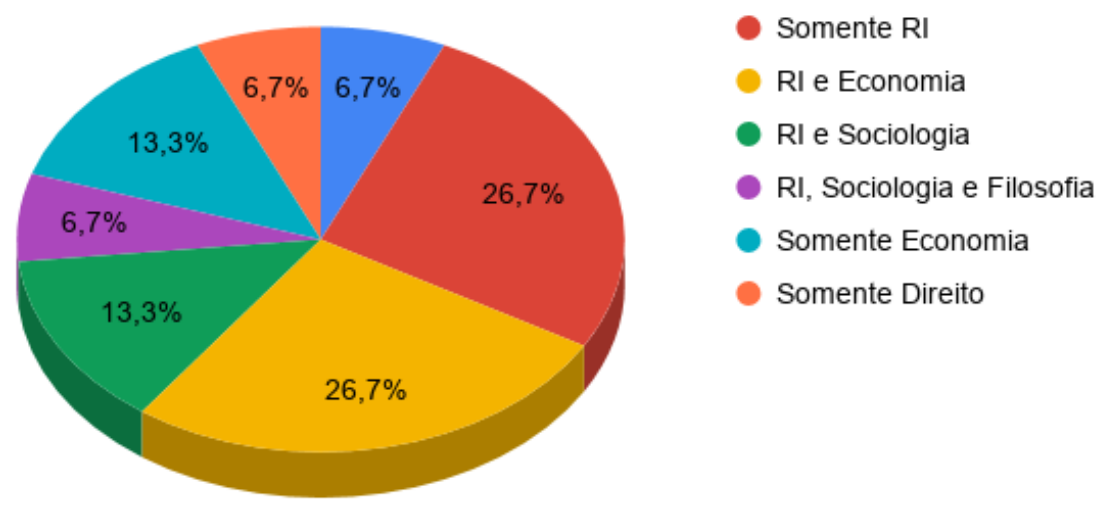

Fonte: Elaboração dos autores.

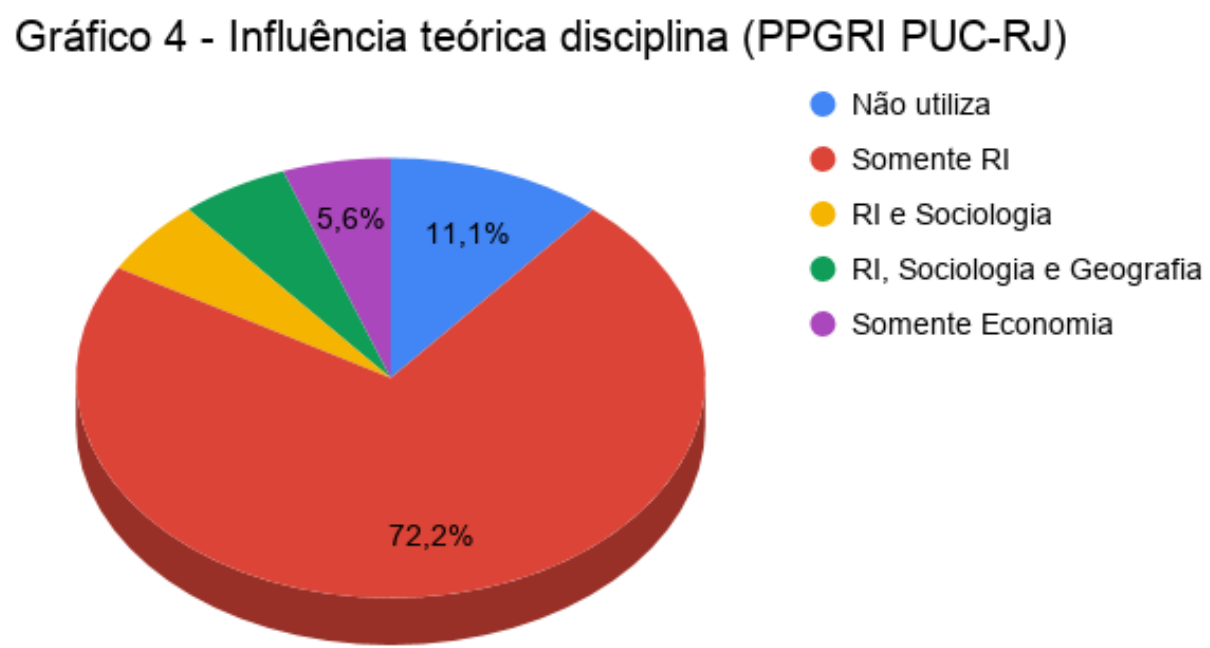

Fonte: Elaboração dos autores.

Ao realizar tabulação mais detalhada das teses que utilizaram TRI em ambos os PPGs, aparecem distintas combinações de vertentes teóricas, tanto na UFRGS quanto na PUC-RJ. É possível visualizarmos a crescente utilização de Teorias de RI construídas na América Latina nas teses da UFRGS e também das abordagens do 
JOCIELI DECOL \& IGOR C. SILVA

Construtivismo, Teoria Crítica, Regionalismo e Análise de Política Externa (APE). Já na PUC-RJ predominam combinações com o Liberalismo e o uso do Construtivismo. Neste último caso, também é notável a quantidade de teses que se utilizam de teorias pós-positivistas/reflexivistas, embora com viés marcado pelo uso ou adaptação teórica das colaborações desenvolvidas no Norte Global.

Tabela 2 - Influência teórica de RI (PPGEEI UFRGS)

\begin{tabular}{lc}
\hline Teoria de Relações Internacionais & $\begin{array}{c}\text { Número } \\
\text { de Teses }\end{array}$ \\
\hline Combinações entre Liberalismo, Realismo e Marxismo & 2 \\
Teorias Latino-americanas (Teoria da Dependência, Teoria de & 3 \\
Amado Cervo) & 1 \\
Realismo & 1 \\
Realismo, Construtivismo, Liberalismo e Novo Regionalismo & 1 \\
Teoria da Dependência + Marxismo & 1 \\
Construtivismo & 1 \\
APE, Realismo, Novo Regionalismo, Teoria Crítica, & \\
Construtivismo e novas abordagens & 1 \\
APE, Teoria Dependência e Novo Regionalismo & 4 \\
Não usam TRI & 15 \\
\hline Total & Fonte: Elaboração dos autores.
\end{tabular}

Tabela 3 - Influência teórica de RI (PPGRI PUC-RJ)

\begin{tabular}{lc}
\hline Teoria de Relações Internacionais & $\begin{array}{c}\text { Número } \\
\text { de Teses }\end{array}$ \\
\hline Construtivismo & 3 \\
Feminismo (1), Pós-Colonialismo + Pós-Estruturalismo (1), Pós- & 3 \\
Estruturalismo (1) & \\
Combinações de Liberalismo + Teoria Crítica; Construtivismo; & 3 \\
Novo Regionalismo & \\
Liberalismo (1) e Realismo (1) & 2 \\
Novo Regionalismo/Escola Inglesa & 2 \\
Marxismo + Teoria Crítica & 1 \\
Realismo + Pós-Estruturalismo & 1 \\
\hline
\end{tabular}


Fonte: Elaboração dos autores.

\section{Considerações finais}

Esse estudo teve como objetivo principal contribuir para o desenvolvimento da disciplina de Relações Internacionais, chamando atenção para as teorizações da periferia, mais especificamente da América Latina e do Brasil sobre o internacional. A partir do debate sobre o processo de construção do conhecimento nas RI foi possível questionar a maneira assimétrica em que este se estabelece e refletir sobre a manutenção de um Centro e uma Periferia no que se refere à construção e difusão de teorias na disciplina. Deste modo, cada seção apresentada teve como função aprofundar a discussão sobre esta temática.

$\mathrm{Na}$ primeira seção do artigo refletimos acerca de conceitos historicamente consolidados como ciência e teoria, questionando o caráter eurocêntrico no qual as $\mathrm{RI}$ se consolidam enquanto área do saber e que constrange a ascensão de formas distintas de teorização. Esse contexto cria um sistema Centro-Periferia no que se refere ao conhecimento na disciplina, o qual se constrói por meio da divisão entre um Norte/Centro responsável construção e reflexão teórica e ao Sul/Periferia o fornecimento de dados e consumo dessas teorias. Para que possamos superar essa lógica precisamos refletir sobre as relações de poder que envolvem a construção e consolidação de conceitos e teorias e que impede a incorporação de teorias do Sul nas RI, essa reflexão é promovida principalmente pelas teorias reflexivistas ou póspositivistas, as quais proporcionam novas maneiras de ver e interpretar o internacional, complexificando e pluralizando as Relações Internacionais. Em um escopo mais amplo, esse movimento tem sido chamado de Teorias do Sul ou Epistemologias do Sul, as quais denunciam a lógica opressora da epistemologia dominante e assim, abrem espaço para novas formas de saber.

$\mathrm{Na}$ segunda seção procuramos elucidar as formulações teóricas construídas no espaço proposto por essa pesquisa: América Latina e Brasil. Podemos perceber que além da configuração Centro-Periferia, outro fator que dificulta a construção de 
teorias é a incorporação de um "complexo de vira-lata intelectual" que permeia essas localidades. No entanto, constatamos ao longo do texto que o Sul, representado aqui pela América Latina e o Brasil, constroem teoria e que estas são de grande importância para uma compreensão mais eficaz do cenário internacional. Por isso, buscamos na seção seguinte avaliar de forma mais profunda, especificamente as formulações brasileiras no século XXI, para entender como o país se relaciona com as TRI.

Na terceira seção apresentamos a análise das teorizações brasileiras em RI na atualidade, a partir das teses de doutorado da PUC-RJ e da UFRGS. Esta foi conduzida por meio da avaliação de três ângulos principais: 1) características gerais da tese; 2) perfil das autoras (es); e 3) relação com teoria. Por meio da leitura do resumo, introdução, conclusão e, quando necessário, do capítulo teórico das teses foi possível visualizar que algumas características permanecem presentes ao longo do tempo com relação ao conhecimento produzido no Brasil em RI: a centralidade da política externa, o Brasil como unidade de análise e a importância do tema desenvolvimento. Além disso, podemos notar o crescente interesse por questões de Segurança Internacional, e a inclusão cada vez maior de obras periféricas nas teses de doutorado brasileiras das duas universidades analisadas. Outra variável importante no que diz respeito ao perfil das autoras (es) das teses é a predominância gritante do gênero masculino e o percentual daqueles (as) que exerceram alguma etapa de sua formação no Norte (33,3\% em ambas).

Por fim, ao avaliarmos a relação das teses com teoria averiguamos que a maioria atribui às teorias um papel central e procura desenvolver a criação/redefinição de conceitos, criação de modelos de análise ou o estabelecimento de explicações causais. Isso demonstra que a atenção dada ao tema é crescente apesar das dificuldades de pensar teoria em um país periférico como o Brasil, marcado pela falta de estrutura material e financeira para a realização de pesquisas e que vem sofrendo, nos últimos anos, ataques constantes por parte do próprio governo às universidades e à educação de um modo geral. Além disso, o país sofre com os altos índices de pobreza e desigualdade, insegurança e instabilidade social. Estes fatores, aliados à estrutura centro-periferia da produção do conhecimento, que destina aos países periféricos o consumo do que é produzido no Norte, constrangem o avanço das teorizações em RI no Brasil. A despeito da ampliação de perspectivas epistemológicas ecléticas (combinações teóricas) e 
adoção de metodologias reflexivistas e críticas, observa-se a dificuldade de proposição de corpos teóricos próprios, de perspectivas sistêmicas (regional e internacional) e de iniciativas teóricas de viés explicativo, o que limita a amplitude e pluralidade das teorias produzidas no Sul.

A análise em diversos ângulos das teses de doutorado da UFRGS e da PUCRJ possibilitou uma melhor compreensão de como o Brasil entende, dialoga e constrói Teoria de Relações Internacionais. Compreendeu-se a partir dessa pesquisa que é preciso transformar as Relações Internacionais, para que então, as diferentes perspectivas sobre o internacional sejam contempladas na disciplina de maneira não hierárquica. Para que isso ocorra, é preciso transcender as fronteiras da disciplina (BLANEY; TICKNER, 2012) impostas ao longo de sua construção moderna/colonial. As RI precisam mudar, mas essa mudança certamente não virá do Norte, o protagonismo será do Sul (PUCHALLA, 1998). Nesse sentido um fator essencial é a clareza de que a atividade acadêmica não é neutra, e sim política (BLANEY; TICKNER, 2012), e que o engajamento nesse âmbito é central para que deixemos de ser dependentes academicamente, economicamente e politicamente. $O$ processo de construção do conhecimento é o debate central neste estudo, pois acreditamos que qualquer mudança profunda e efetiva em uma sociedade se inicia pela educação, pela maneira como construímos, repassamos e absorvemos a realidade. Por isso, é necessário ampliarmos as lentes pelas quais entendemos o mundo, deixar de vê-lo por meio apenas das lentes ocidentais. Precisamos nos posicionar como agentes, enxergar o mundo também pelas nossas lentes, periféricas sim, mas imbuídas de muita riqueza, cultural, social, política e teórica.

\section{Referências}

ACHARYA, Acharya; BUZAN, Barry. Why Is There No Non-Western International Relations Theory? An Introduction. In: ACHARYA, Acharya.; BUZAN, Barry (Org). Non-Western International Relations Theory: Perspectives on and beyond Asia. Abingdon, UK: Routledge, 2010.

AYOOB, Mohammed. The Third World Security Predicament: State Making, Regional Conflict, and the International System. Boulder: Lynne Rienner Publishers, 1995.

BALLESTRIN, Luciana. O giro decolonial e a América Latina. Disponível em: http://anpocs.com/index.php/encontros/papers/36-encontro-anual-da-anpocs/mr3/mr19/8321-o-giro-decolonial-e-a-america-latina/file 
BALLESTRIN, Luciana. Teoria Política da Decolonização: uma perspectiva latinoamericana. IX Encontro ABCP. Brasília, 2014. Dísponível em: <http://www.encontroabcp2014.cienciapolitica.org.br/resources/anais/14/1403747208 ARQUIVO_ABCP2014Ballestrin.pdf>

BARASUOL, Fernanda, B. Teorização (In) Dependente: as Teorias de Relações Internacionais e a formulação da Política Externa Brasileira. Trabalho final de graduação. Universidade Federal do Rio Grande do Sul, Porto Alegre, 2010.

BARASUOL, Fernanda, B. Da dependência à globalização: contribuições brasileiras aos estudos de economia política internacional. Seminário Nacional de PósGraduação em Relações Internacionais, v. 1, 2012.

BERNAL-MEZA, Raúl. América Latina en el Mundo: el pensamiento latinoamericano y la teoría de relaciones internacionales. Buenos Aires: Nuevo Hacer, 2005.

BERNAL-MEZA, Raúl. Contemporary Latin American thinking on Inernational Relations: theoretical, conceptual and methodological contributions. Rev. Bras. Polít. Int., 59(1): e005, 2016.

CAMPOS, Rodrigo Duque, E. Filosofia da Ciência e Religiosidade: Problemas do Sagrado na Teoria de Relações Internacionais. Trabalho de Conclusão de Curso, Universidade Federal do Pampa: Santana do Livramento, 2014.

CARDOSO, Fernando,H.; FALLETO, Enzo. Dependência e Desenvolvimento da América Latina. 3 ed. Rio de Janeiro: Zahar, 1970.

CASTRO-GÓMEZ, Santiago; GROSFOGUEL, Ramón. El giro decolonial: reflexiones para una diversidad epistémica más allá del capitalismo global. Siglo del Hombre Editores, 2007.

CERVO, Amado Luiz. Política exterior e relações internacionais do Brasil: enfoque paradigmático. Revista Brasileira de Política Internacional, v. 46, n. 2, p. 5-25, 2003.

DE LIMA, Maria Regina Soares. A economia política da política externa brasileira: uma proposta de análise. Contexto Internacional, v. 12, n. 1, p. 7, 1990.

DE SOUSA SANTOS, Boaventura; MENESES, Maria Paula. Introdução. In: DE SOUSA SANTOS, B; MENESES, M. (Orgs). Epistemologias do Sul. 1. ed. Coimbra: Edições Almedida.sa, 2009.

DEVÉS-VALDÉS, Eduardo. Cómo pensar los asuntos internacionales-mundiales a partir del pensamiento latinoamericano: Análisis de la teorización. História Unisinos, v. 17 , n. 1, p. 48-60, 2013.

DOS SANTOS, Norma Breda; FONSECA, Fúlvio Eduardo. A pós-graduação em relações internacionais no Brasil. Contexto Internacional, v. 31, n. 2, p. 353, 2009.

DIAS, Marcelo Francisco. Do estruturalismo da CEPAL à teoria da dependência: continuidades e rupturas no estudo do desenvolvimento periférico. 2012.197 p. Tese de Doutorado. Universidade de São Paulo. São Paulo, 2012. 
DIRLIK, Arif. The end of colonialism? The colonial modern in the making of global modernity. boundary 2, v. 32, n. 1, p. 1-31, 2005.

ESCOBAR, Arturo. Mundos y conocimientos de otro modo. Tabula rasa, v. 1, n. 5186, 2003.

ESCUDÉ, Carlos. An introduction to Peripheral Realism and its Implications for the Interstate System: Argentina and the Cóndor II Missile Project. In: NEUMAN, Stephanie G. (org). International relations theory and the Third World. Nova Iorque, 1998.

FIORI, José Luís. Maria da Conceição Tavares e a hegemonia Americana. Lua Nova, n.50, 2000.

GANDHI, Leela. Postcolonial theory: A critical introduction. Columbia University Press, 1998.

GROVOGUI, Siba. A revolution nonetheless: The Global South in international relations. The Global South, v. 5, n. 1, p. 175-190, 2011.

HERZ, Mônica. O crescimento da área de relações internacionais no Brasil. Contexto internacional, v. 24, n. 1, p. 7-40, 2002.

HOFFMANN, Stanley. An American social science: international relations. Daedalus, p. 41-60, 1977.

HOLLIS, Martin; SMITH, Steve. Explaining and Understanding International Relations. 1990.

JACKSON, Robert; SØRENSEN, Georg. Introduction to international relations: theories and approaches. 5.ed. UK:Oxford University Press, 2013.

JAGUARIBE, Helio. Autonomía periférica y hegemonía céntrica. Estudios internacionales, p. 91-130, 1979.

JATOBÁ, Daniel. Teoria das Relações Internacionais. São Paulo: Saraiva, 2013.

JULIÃO, Taís Sandrim. Teoria e História das Relações Internacionais: Uma Escola Latino-Americana? Conjuntura Austral, v. 2, n. 7, p. Pág. 51-66, 2011.

KURKI, Milja; WIGHT, Colin. International Relations and Social Science. In: DUNNE, Tim; KURKI, Milja; SMITH, Steve. International Relations Theories: discipline and diversity. 3.ed. Oxford University Press, 2013.

LAFER, Celso. A identidade internacional do Brasil e a política externa brasileira: passado, presente e futuro. Editora Perspectiva, 2001.

LANDER, E. Ciências sociais: saberes coloniais e eurocêntricos. In LANDER, E. (Org). A Colonialidade do Saber: eurocentrismo e ciências sociais. Perspectivas latino-americanas. Buenos Aires: Consejo Latinoamericano de Ciencias SocialesCLACSO, 2005. 
LESSA, A. Instituições, atores e dinâmicas do ensino e da pesquisa em Relações Internacionais no Brasil: o diálogo entre a história, a ciência política e os novos paradigmas de interpretação (dos anos 90 aos nossos dias). Rev. Bras. Polít. Int, v. 48, n. 2, p. 169-184, 2005.

LESSA, Antonio Carlos; COUTO, Leandro Freitas; DE SOUZA FARIAS, Rogério. Distanciamento versus engajamento: alguns aportes conceituais para a análise da inserção do multilateralismo brasileiro (1945-1990). Contexto Internacional, v. 32, n. 2, p. 333, 2010.

LUGONES, María. Rumo a um feminismo descolonial. Estudos Feministas, v. 22, n. 3, 2014.

LYNCH, Christian Edward Cyril. Por que pensamento e não teoria? A imaginação político-social brasileira e o fantasma da condição periférica (1880-1970). Revista Dados, v. 56, n. 4, 2013.

MALDONADO-TORRES, Nelson. Sobre la colonialidad del ser: contribuciones al desarrollo de un concepto. El giro decolonial. Reflexiones para una diversidad epistémica más allá del capitalismo global, p. 127-167, 2007.

MIGNOLO, Walter. The Geopolitics of Knowledge and the Colonial Difference. Duke University Press, The South Atlantic Quarterly, 2002. Disponível em: <http://www.unice.fr/crookall-cours/iup_geopoli/docs/Geopolitics.pdf.> Acesso em: Ago. 2015.

MIGNOLO, Walter. A colonialidade de cabo a rabo: o hemisfério ocidental no horizonte conceitual da modernidade. In: LANDER, Edgardo et al. (Ed.). A colonialidade do saber: eurocentrismo e ciências sociais: perspectivas latinoamericanas. CLACSO, Consejo Latinoamericano de Ciencias Sociales, p. 71-103, 2005.

NEUFELD, M. The reflexive turn and International Relations theory. 1991.

NEUMAN, Sthepanie. (Org). International Relations Theory and the Third World. Nova lorque, Copyright, 1998.

NOGUEIRA, João Pontes; MESSARI, Nizar. Teoria das relações internacionais. Elsevier, 2005.

OLIVA, Alberto. Teoria do conhecimento. Zahar, p. 1-19, 2011.

PECEQUILO, Cristina. Soreanu. Introdução às Relações Internacionais: temas, atores e visões. Vozes, 2004.

PUCHALLA, Donald. Third World Thinking and Contemporany International Relations. In:

NEUMAN, Stephanie. (Org). International Relations Theory and the Third World. Nova lorque, Copyright, 1998. 
QUIJANO, Aníbal. Colonialidade do Poder, Eurocentrismo e América. In: LANDER, Edgardo (Org). A Colonialidade do Saber: eurocentrismo e ciências sociais. Perspectivas latino-americanas. Buenos Aires: Consejo Latinoamericano de Ciencias Sociales-CLACSO, 2005.

QUIJANO, Aníbal. Colonialidade do poder e classificação social. In: DE SOUSA SANTOS, Boaventura.; MENESES, Maria Paula. (Orgs). Epistemologias do Sul. Coimbra: Edições Almedida.sa, 2009.

RAPOPORT, Mario. Historia económica, política y social de la Argentina (18802003). Machi, 2000.

RUIZ, José. Briceno. A contribuição latino-americana para a teoria das relações internacionais. In: PREBISCH, Raúl. et al. O manifesto latino-americano: e outras ensaios. São Paulo: Contraponto, 2011.

RUSSEL, Roberto.; TOKÁTLIAN, Juan Gabriel. De la autonomía antagónica a la autonomía relacional: una mirada teórica desde el Cono Sur. Perfiles Latino Americanos, n. 21, p. 159-194. 2002.

SAID. Edward. W. Orientalismo: O Oriente como invenção do Ocidente. Tradução Tomás Rosa Bueno. São Paulo: Companhia das Letras, 1990.

SLATER, David. Geopolitics and the post-colonial: rethinking North-South relations. John Wiley \& Sons, 2008.

SMITH, Steve. New approaches to international theory. In:BAYLES, John; SMITH, Steve. The Globalization of World Politics, 1997.

SMITH, Steve. Introduction: Diversity and Disciplinarity in International Relations Theory. In: DUNNE, Tim; KURKI, Milja; SMITH, Steve. International Relations Theories: discipline and diversity. 3.ed. Oxford University Press, 2013.

TICKNER, Arlene. Relaciones de conocimiento centro-periferia: hegemonía, contribuciones locales e hibridización. Politai, v.3, n.4, 2012. Disponível em: <http://revistas.pucp.edu.pe/index.php/politai/article/view/14105/14721> Acesso em: 13 jun. 2015.

TICKNER, Arlene. Core, Periphery and (neo)imperialist International Relations. European Journal of International Relations. p. 627-646, 2013. Disponível em: http://ejt.sagepub.com/cgi/doi/10.1177/1354066113494323. Acesso em: Out.2016.

TICKNER, Arlene; BLANEY, David, L. Introduction: Thinking difference. In: TICKNER, Arlene; BLANEY, David, .L. (Org). Thinking international relations differently. EUA e Canadá: Routledge, 2012.

TICKNER, Arlene; BLANEY, David, L. Introduction: Claiming the international beyond IR. In: TICKNER, Arlene.; BLANEY, David, L. Claiming the International. EUA e Canadá: Routledge, 2013.

TICKNER, Arlene; WÆVER, Ole. (Org). International relations scholarship around the world. EUA e Canadá: Routledge, 2009. 
TOMASSINI, Luciano et al. Nuevas formas de concertación regional en América Latina: el sistema internacional y América Latina. RIAL, 1990.

VARGAS, João Augusto Costa. Um mundo que também é nosso: o pensamento e a trajetória diplomática de Araujo Castro. Brasília: FUNAG, 2013.

VIGEVANI, Tullo; CEPALUNI, Gabriel. A política externa de Lula da Silva: a estratégia da autonomia pela diversificação. Contexto internacional, v. 29, n. 2, p. 273-335, 2007.

VIGEVANI, Tullo; THOMÁZ, Laís Forti; LEITE, Lucas Batista. As Relações Internacionais no Brasil: notas sobre o início de sua institucionalização. InterRelações, p. 5-11, 2014.

VIZENTINI, Paulo Fagundes. A evolução da produção intelectual e dos estudos acadêmicos de relações internacionais no Brasil. In: SOMBRA SARAIVA, José. Flávio; CERVO, Amado. O crescimento das Relações Internacionais no Brasil. Brasília, IBRI, 2005.

VIZENTINI, Paulo Fagundes. O descompasso entre as nações. In: SADER, Emir (Org.) Os porquês da desordem mundial. Mestres explicam a globalização. Rio de Janeiro: Record, 2004.

WAEVER, Ole. The rise and fall of the inter-paradigm debate. In: SMITH, Steve; BOOTH, Ken; ZALEWSKI, Marsya. International Theory: Positivism and Beyond. Cambridge University Press, 1996. 